\title{
Molecular Imaging of Gastroenteropancreatic Neuroendocrine Tumors: Current Status and Future Directions
}

\author{
Christophe M. Deroose ${ }^{1}$, Elif Hindié2,3, Electron Kebebew ${ }^{4}$, Bernard Goichot ${ }^{5}$, Karel Pacak ${ }^{6}$, David Taïeb ${ }^{7-9}$, \\ and Alessio Imperiale ${ }^{10,11}$ \\ ${ }^{1}$ Nuclear Medicine, University Hospitals Leuven, Leuven, Belgium; ${ }^{2}$ Nuclear Medicine, Haut-Lévêque Hospital, University of \\ Bordeaux, France; ${ }^{3}$ LabEx TRAIL, University of Bordeaux, France; ${ }^{4}$ Endocrine Oncology Branch, National Cancer Institute, \\ NIH, Bethesda, Maryland; ${ }^{5}$ Internal Medicine, Strasbourg University Hospitals, Strasbourg, France; ${ }^{6}$ Section on Medical \\ Neuroendocrinology, Eunice Kennedy Shriver NICHD, NIH, Bethesda, Maryland; ${ }^{7}$ Nuclear Medicine, La Timone University Hospital, \\ Aix-Marseille University, Marseille, France; ${ }^{8}$ European Center for Research in Medical Imaging, Marseille, France; ${ }^{9}$ INSERM \\ UMR1068, Marseille, France; ${ }^{10}$ Biophysics and Nuclear Medicine, Strasbourg University Hospitals, Strasbourg, France; and \\ ${ }^{11}$ ICube, UMR 7357, University of Strasbourg/CNRS and FMTS, Faculty of Medicine, University of Strasbourg, Strasbourg, France
}

Learning Objectives: On successful completion of this activity, participants should be able to (1) summarize the main clinical features of gastroenteropancreatic neuroendocrine tumors; (2) describe the specific mechanisms of uptake of radiotracers and identify the relation of imaging phenotype with site of origin and tumor grade; and (3) recommend the best imaging modalities across the different tumor subtypes for imaging and for selecting candidates for peptide receptor radionuclide therapy.

Financial Disclosure: Dr. Deroose is a consultant/advisor for Sirtex and Ipsen, is a meeting participant/lecturer for Bayer, and is involved in a scientific study/ trial for AAA. The authors of this article have indicated no other relevant relationships that could be perceived as a real or apparent conflict of interest.

CME Credit: SNMMI is accredited by the Accreditation Council for Continuing Medical Education (ACCME) to sponsor continuing education for physicians. SNMMI designates each JNM continuing education article for a maximum of 2.0 AMA PRA Category 1 Credits. Physicians should claim only credit commensurate with the extent of their participation in the activity. For CE credit, SAM, and other credit types, participants can access this activity through the SNMMI website (http://www.snmmilearningcenter.org) through December 2019.

Through diagnostic imaging and peptide receptor radionuclide therapy, nuclear medicine has earned a major role in gastroenteropancreatic neuroendocrine tumors (GEP NETs). GEP NETs are diagnosed fortuitously or on the basis of symptoms or hormonal syndrome. The functional tumor characteristics shown by radionuclide imaging allow for more accurate staging and treatment selection. Tumor grade helps determine which tracer should be selected. In the past, ${ }^{111}$ In-pentetreotide has been successful in well-differentiated (G1 and G2) tumors. However, PET/CT imaging with novel somatostatin analogs (e.g., ${ }^{68} \mathrm{Ga}-\mathrm{DOTATOC},{ }^{68} \mathrm{Ga}$-DOTATATE, ${ }^{68} \mathrm{Ga}-\mathrm{DOTANOC}$, and ${ }^{64} \mathrm{Cu}-$ DOTATATE) now offers improved sensitivity. ${ }^{18} \mathrm{~F}$-fluorodihydroxyphenylalanine $\left({ }^{18} \mathrm{~F}-\mathrm{FDOPA}\right)$ is another interesting radiopharmaceutical. ${ }^{18} \mathrm{~F}$-FDOPA sensitivity is influenced by a tumor's capacity to take up, decarboxylate, and store amine precursors. ${ }^{18} \mathrm{~F}$-FDOPA sensitivities are highest in ileal NETs and may also be helpful in insulinomas. A high uptake of ${ }^{18} \mathrm{~F}-\mathrm{FDG}$ with a low uptake of somatostatin analog usually indicates poorly differentiated tumors (G3). Starting from these principles, this article discusses theranostic approaches to GEP NETs, taking into account both primary and metastatic lesions.

Key Words: gastroenteropancreatic neuroendocrine tumors (GEP NETs); PET/CT; ${ }^{68} \mathrm{Ga}$-somatostatin analogues; ${ }^{18} \mathrm{~F}-\mathrm{FDOPA} ;{ }^{18} \mathrm{~F}-\mathrm{FDG}$

J Nucl Med 2016; 57:1949-1956

DOI: 10.2967/jnumed.116.179234

Received Jul. 21, 2016; revision accepted Oct. 17, 2016.

For correspondence or reprints contact: Alessio Imperiale, Biophysics and Nuclear Medicine, Hautepierre University Hospital, 1, Avenue Molière, 67098 Strasbourg Cedex 09, France.

E-mail: alessio.imperiale@chru-strasbourg.fr

Published online Nov. 3, 2016.

COPYRIGHT (C 2016 by the Society of Nuclear Medicine and Molecular Imaging, Inc. astroenteropancreatic neuroendocrine tumors (GEP NETs) are heterogeneous epithelial neoplasms that account for about $60 \%$ of all NETs. The annual age-adjusted incidence of NETs increased from $1.09 / 100,000$ in 1973 to $5.25 / 100,000$ in 2004, probably because of the improved sensitivity of diagnostic techniques $(1,2)$.

\section{OVERVIEW OF GEP NETS}

\section{Presentation}

There are 3 types of gastric NET. Type 1 is the most frequent; the lesions are usually smaller than $1 \mathrm{~cm}$, multiple, benign, and associated with atrophic gastritis. Type 2 is rare and is associated with Zollinger-Ellison syndrome. Type 3 is also rare; the lesions are commonly solitary and potentially malignant. Determining the tumor subtype is crucial for planning the optimal therapeutic strategy (3).

Duodenal NETs often present as a small lesion limited to the submucosa or mucosa, arise most frequently in the first or second part of the duodenum, and can be either sporadic or associated with multiple endocrine neoplasia type 1 (3).

Pancreatic NETs are classified as either nonfunctional or functional, with most being nonfunctional and typically diagnosed at an advanced stage. Symptoms are associated with tumor bulk and metastatic spread. Functional pancreatic NETs cause clinical syndromes related to hormone hypersecretion according to the cell of origin (e.g., insulin, gastrin, glucagon, or vasoactive intestinal peptide). Some pancreatic NETs occur in the context of inherited genetic syndromes (4).

Small-intestine NETs (ileum/jejunum) are often serotonin-secreting, are multifocal in about $30 \%$ of cases, and appear as polypoid lesions or hypervascular parietal thickening. Small-intestine NETs are usually called functional when serotonin secretion is responsible for a carcinoid 
syndrome, which typically includes flushing and diarrhea and is usually associated with the presence of liver metastases. Carcinoid disease of the right heart, related to fibrosis and tricuspid valve insufficiency, is a severe complication with a deleterious impact on survival (5).

Colonic and rectal NETs are rarely functional and are often diagnosed on routine colonoscopy. Colonic NETs are usually large at diagnosis and often metastatic to the liver, lymph nodes, mesentery, or peritoneum. Abdominal pain, gastrointestinal bleeding, and weight loss are the most common symptoms. Rectal NETs are usually small, polypoid lesions and are rarely metastatic (6). Finally, NETs of the appendix are often incidentally discovered during surgery for appendicitis, and most are stage I.

\section{Tumor Grading and Disease Staging}

According to the 2010 World Health Organization classification (7), GEP NETs are graded as follows: G1 tumors are usually slowly evolving ( $\mathrm{Ki}-67 \leq 2 \%$, mitotic count $<2$ ); G2 tumors constitute a more heterogeneous, well-differentiated, aggressive group (Ki-67 $>2 \%$ and $\leq 20 \%$, mitotic count of $2-20$ ); and G3 tumors are poorly differentiated carcinomas characterized by aggressive behavior and poor survival (Ki-67 $>20 \%$ or mitotic count $>20$ ). A small percentage of well-differentiated tumors have a Ki-67 of more than $20 \%$ (G3) and have a better outcome than classic G3 neuroendocrine carcinomas $(8)$.

GEP NET staging relies on the criteria of the European Neuroendocrine Tumor Society and the American Joint Committee on Cancer/Union for International Cancer Control. Stages 0IIIa correspond to nonmetastatic tumors, IIIb to tumors with nodal involvement, and IV to distant metastases $(9,10)$.

\section{Role of Imaging}

A multidisciplinary approach combining morphologic and functional imaging modalities is important for accurate staging and treatment. Contrast-enhanced CT and MRI provide detailed, anatomic information on the primary-tumor location and identify regional and distant metastases-information that is needed for optimal surgical intervention, treatment selection, and identification of persistent or recurrent disease (Table 1). Imaging with PET/CT or SPECT/CT using adequate tracers is also essential in the management of patients with GEP NETs. These functional imaging modalities allow for accurate delineation of disease extent at both initial staging and follow-up and can also identify an occult primary tumor, a task that is sometimes challenging but is helpful in optimizing the therapeutic strategy, especially in patients with metastatic disease. Additionally, functional imaging allows for noninvasive characterization of tumoral functional status and heterogeneity based on analysis of the uptake intensity of target-specific radiotracers (11). Finally, functional imaging can offer a better prognostic stratification and refinement of therapeutic strategies, allowing for a personalized theranostic approach to the management of GEP NETs (Table 2).

\section{CONVENTIONAL MORPHOLOGIC PROCEDURES}

\section{Primary Tumor Detection}

Endoscopy is the preferred investigation to locate gastric, duodenal, colorectal, and some terminal ileal NETs (12). In patients suspected of having small-bowel tumors, enteroclysis and bariumcontrast examinations have been replaced by multiplanar contrastenhanced CT or MRI followed by small-bowel distention before focused CT or MR enterography or enteroclysis. Capsule endoscopy enables analysis of the entire small bowel. However, it has moderate sensitivity and does not allow for tumor biopsy to establish a pathologic diagnosis. There is also a risk of retention. In patients with suspected pancreatic NETs, multiphase CT or MRI is the first-line

TABLE 1

Currently Available Endoscopic and Anatomic-Imaging Techniques for GEP NET Investigation

\begin{tabular}{|c|c|c|c|c|c|}
\hline Characteristic & TAUS & EUS & Video capsule & $\mathrm{CT}^{*}$ & $\mathrm{MRI}^{*}$ \\
\hline Use & $\begin{array}{l}\text { Detection of } \\
\text { primary } \\
\text { GI NET } \\
\text { (solid } \\
\text { organs } \\
\text { only) }\end{array}$ & $\begin{array}{l}\text { Detection of gastric, } \\
\text { duodenal and } \\
\text { rectal primary NETs; } \\
\text { diagnostic biopsy }\end{array}$ & $\begin{array}{l}\text { Detection of } \\
\text { esophageal, } \\
\text { gastric, duodenal, } \\
\text { and small-bowel } \\
\text { primary NETs }\end{array}$ & $\begin{array}{l}\text { Staging and follow-up } \\
\text { (first-choice modality); } \\
\text { identification of primary } \\
\text { site; evaluation of local } \\
\text { extent; assessment of } \\
\text { metastases }\end{array}$ & $\begin{array}{l}\text { Detection and } \\
\text { assessment of } \\
\text { liver metastases } \\
\text { (first-choice modality) }\end{array}$ \\
\hline Sensitivity & $\begin{array}{l}\text { Limited; high } \\
\text { interoperator } \\
\text { variability }\end{array}$ & High & Moderate & $\begin{array}{l}\text { Can be enhanced by } \\
\text { enterography } \\
\text { and enteroclysis }\end{array}$ & $\begin{array}{l}\text { High for bone marrow } \\
\text { metastases; can be } \\
\text { enhanced by } \\
\text { enterography } \\
\text { and enteroclysis }\end{array}$ \\
\hline $\begin{array}{l}\text { Radiation } \\
\text { exposure }\end{array}$ & No & No & No & Yes & No \\
\hline Other & $\begin{array}{l}\text { Is widely } \\
\text { available }\end{array}$ & Is invasive & $\begin{array}{l}\text { Can analyze } \\
\text { entire bowel }\end{array}$ & Is widely available & $\begin{array}{l}\text { Uses gadolinium chelate, } \\
\text { which is safer than CT } \\
\text { iodine agents as regards } \\
\text { allergic reactions and } \\
\text { nephrotoxicity }\end{array}$ \\
\hline
\end{tabular}

*Multiplanar contrast-enhanced images

TAUS = transabdominal ultrasound; EUS = endoscopic ultrasound. 
TABLE 2

Currently Available Functional-Imaging Techniques for GEP NET Investigation

\begin{tabular}{|c|c|c|c|c|c|}
\hline Characteristic & $\begin{array}{c}111 \text { In-pentetreotide } \\
\text { SPECT/CT }\end{array}$ & $\begin{array}{l}\text { 123I-MIBG } \\
\text { SPECT/CT }\end{array}$ & ${ }^{68} \mathrm{Ga}-\mathrm{SSA}$ PET/CT & 18F-FDOPA PET/CT & ${ }^{18} \mathrm{~F}-\mathrm{FDG} \mathrm{PET} / \mathrm{CT}$ \\
\hline Use & $\begin{array}{l}\text { Primary staging; } \\
\text { restaging; } \\
\text { patient selection } \\
\text { before PRRT }\end{array}$ & $\begin{array}{l}\text { Patient selection } \\
\text { before }{ }^{131} \mid-\mathrm{MIBG} \\
\text { radiometabolic } \\
\text { treatment }\end{array}$ & $\begin{array}{l}\text { Primary staging; } \\
\text { restaging; patient } \\
\text { selection before } \\
\text { PRRT; imaging } \\
\text { when primary site } \\
\text { is unknown }\end{array}$ & $\begin{array}{l}\text { Primary staging; } \\
\text { imaging when } \\
\text { primary site is } \\
\text { unknown (based on } \\
\text { presumption of } \\
\text { ileal origin); } \\
\text { (restaging?) }\end{array}$ & $\begin{array}{l}\text { Prognostic stratification; } \\
\text { imaging of high-grade } \\
\text { G2/G3 NETs }\end{array}$ \\
\hline $\begin{array}{l}\text { Spatial } \\
\text { resolution }\end{array}$ & $\operatorname{Low}(>10 \mathrm{~mm})$ & Low $(>10 \mathrm{~mm})$ & High (5 mm) & High (5 mm) & High (5 mm) \\
\hline $\begin{array}{l}\text { Procedure } \\
\text { length }\end{array}$ & $2 d$ & $2 d$ & $1 d$ & $1 d$ & $1 d$ \\
\hline $\begin{array}{l}\text { Radiation } \\
\text { exposure }\end{array}$ & Moderate & Mild & Mild & Mild & Mild \\
\hline Other & $\begin{array}{l}\text { Is approved for } \\
\text { NET imaging }\end{array}$ & $\begin{array}{l}\text { Has low sensitivity } \\
\text { for GEP NETs }\end{array}$ & $\begin{array}{l}\text { Will soon replace } \\
\text { conventional SSTR } \\
\text { scintigraphy }\end{array}$ & $\begin{array}{l}\text { May be less } \\
\text { sensitive } \\
\text { than }{ }^{68} \mathrm{Ga}-\mathrm{SSA} \\
\text { PET/CT for nonileal } \\
\text { GEP NETs }\end{array}$ & $\begin{array}{l}\text { Is widely } \\
\text { available }\end{array}$ \\
\hline
\end{tabular}

imaging option. Normally presenting with hypervascular characteristics, pancreatic NETs are best visualized in the late arterial phase of contrast enhancement. When the available imaging options fail to detect a primary tumor, endoscopic ultrasound may also be of help to obtain a tissue sample for pathologic analysis and to estimate the tumor grade (12).

\section{Tumor Extent and Metastatic Spread}

Contrast-enhanced CT is usually the first procedure in tumor staging, as it is able to identify mesenteric, retroperitoneal, or perigastric metastatic lymph nodes. Mesenteric invasion by carcinoid typically appears as a spiculated mass near the primary tumor and is variably associated with central calcifications. As generally observed in NETs, hepatic metastases are typically hypervascularized in the arterial phase, with washout in the late phase on multiphasic contrast-enhanced CT or MRI. MRI is considered the first choice for anatomic imaging of liver metastases. As NET lesions typically appear hyperintense on T1-weighted MRI sequences and hypointense on T2-weighted MRI sequences, diffusionweighted imaging and apparent diffusion coefficients improve MRI detection of liver metastases.

\section{RADIONUCLIDE IMAGING}

The overexpression of specific membrane receptors, as well as the ability of cells to take up amine precursors in NETs, has been exploited for radiotracer development. Moreover, glycolytic metabolism, which is not a specific energetic pathway of well-differentiated NETs but is seen in less-differentiated NETs, has also been exploited. A personalized nuclear medicine evaluation can now be offered to patients, taking into consideration their clinical presentation and their biologic and histologic tumor characteristics.

\section{Radiolabeled Somatostatin Analogs}

Six human subtypes of somatostatin receptors (SSTRs) have been described (1, 2A, 2B, 3, 4, and 5) (13). Most GEP NETs have moderate-to-high overexpression of SSTRs, most frequently subtype 2A (13). Synthetic somatostatin analogs (SSAs), such as the 8amino-acid derivative octreotide, have been radiolabeled with $\gamma$-emitters $\left({ }^{111} \mathrm{In},{ }^{123} \mathrm{I}\right.$, or $\left.{ }^{99 \mathrm{~m}} \mathrm{Tc}\right)$. One of these radiopharmaceuticals, ${ }^{111}$ In-pentetreotide, has been successfully used for over 2 decades. ${ }^{111}$ In-penetreotide offers high sensitivity and specificity for grade 1 and 2 NETs and has outperformed ${ }^{123}$ I-metaiodobenzylguanidine ( ${ }^{123}$ I-MIBG), with sensitivities of $90 \%$ and $53 \%$, respectively (14).

A novel class of somatostatin analogs labeled with the positronemitting radionuclide ${ }^{68} \mathrm{Ga}$ for PET/CT imaging has emerged as the current gold standard for NETs. ${ }^{68} \mathrm{Ga}$ has a half-life of $68 \mathrm{~min}$ and can be obtained from a ${ }^{68} \mathrm{Ge} /{ }^{68} \mathrm{Ga}$ generator (half-life, $271 \mathrm{~d}$ ). ${ }^{68} \mathrm{Ga}$ can be attached to biomolecules through chelators (e.g., DOTA). Labeling is usually done on-site, as the limited ${ }^{68} \mathrm{Ga}$ half-life makes off-site transport logistically challenging.

There are several ${ }^{68} \mathrm{Ga}$-labeled tracers that have been described and are in clinical use $\left({ }^{68} \mathrm{Ga}\right.$-DOTATOC, ${ }^{68} \mathrm{Ga}$-DOTATATE, and ${ }^{68} \mathrm{Ga}$-DOTANOC, collectively referred to as ${ }^{68} \mathrm{Ga}$-DOTA-peptides). In June 2016, the Food and Drug Administration approved a kit for synthesis of ${ }^{68} \mathrm{Ga}$-DOTATATE. All ${ }^{68} \mathrm{Ga}$-DOTA-peptides have a high affinity for SSTR2, the most overexpressed SSTR subtype. ${ }^{68} \mathrm{Ga}-$ DOTANOC is the only ligand that has a high affinity for SSTR5 (half-maximal inhibitory concentration, $7.2 \mathrm{nM}$, vs. $>70 \mathrm{nM}$ for the other ligands).

${ }^{68}$ Ga-DOTA-peptides display a higher affinity to SSTR2 than does ${ }^{111}$ In-pentetreotide: the half-maximal inhibitory concentration is $22 \mathrm{nM}$ for ${ }^{111} \mathrm{In}$-pentetreotide, versus $2.5,0.2$, and $1.9 \mathrm{nM}$ for ${ }^{68} \mathrm{Ga}$-DOTATOC, ${ }^{68} \mathrm{Ga}$-DOTATATE (15), and ${ }^{68} \mathrm{Ga}$-DOTANOC, respectively (16). Semiquantitative PET parameters $\left(\mathrm{SUV}_{\text {max }}, \mathrm{SUV}_{\text {mean }}\right)$ have been shown to correlate with receptor density up to an $\mathrm{SUV}_{\text {mean }}$ of 25, above which the SUV tends to underestimate the receptor density (17).

Combined with the physical advantages of PET/CT cameras (higher spatial resolution and higher physical sensitivity), these improved pharmacologic properties allow for the detection of smaller 
lesions or the detection of lesions with moderate SSTR expression, resulting in a higher sensitivity and diagnostic accuracy (Figs. 1 and 2).

A prospective study in the United States by Sadowski et al. (18) on 131 patients confirmed the superiority of ${ }^{68} \mathrm{Ga}$-DOTATATE PET/ CT over conventional ${ }^{111}$ In-pentetreotide SPECT/CT and CT. ${ }^{68} \mathrm{Ga}-$ DOTATATE PET/CT detected $95.1 \%$ of lesions, whereas anatomic imaging detected $45.3 \%$ and ${ }^{111}$ In-pentetreotide SPECT/CT detected $30.9 \%$. Therapy decisions were changed on the basis of ${ }^{68} \mathrm{Ga}$-DOTATATE PET/CT results in one third of patients (18).

Other groups have previously reported a similar impact of ${ }^{68} \mathrm{Ga}-$ peptide PET/CT on clinical management. Frilling et al. studied 52 patients, $60 \%$ of whom had a change in therapeutic plan after ${ }^{68} \mathrm{Ga}-$ DOTATOC PET/CT revealed findings different from those on CT or MRI (19). In 7 of the 15 patients screened for liver transplantation, extrahepatic metastases unseen by CT or MRI were documented on ${ }^{68} \mathrm{Ga}$-DOTATOC PET/CT (19). Ruf et al. scanned 64 patients with multiphase contrast-enhanced CT as the CT component of ${ }^{68} \mathrm{Ga}-$ DOTATOC PET/CT and saw an impact on therapeutic management in 24 of them (38\%) (20). Therefore, a combination of ${ }^{68} \mathrm{Ga}$-peptide PET with optimized multiphase CT can result in better patient management.

The detection of the primary site in patients presenting with a neuroendocrine cancer of unknown primary is a major advantage of ${ }^{68} \mathrm{Ga}$-peptide PET/CT. In a series of 38 such patients, contrastenhanced ${ }^{68} \mathrm{Ga}$-DOTATATE PET/CT demonstrated a significantly higher sensitivity ( $94 \%$ vs. $63 \%$ ) and accuracy ( $87 \%$ vs. $68 \%$ ) than contrast-enhanced CT (21). In another series of 29 patients with proven NET metastases without a primary lesion discovered on conventional imaging, ${ }^{68} \mathrm{Ga}$-DOTATATE PET/CT detected the occult lesion in 17 of the patients $(58.6 \%)$ (22). Therefore, on the basis of these studies, ${ }^{68} \mathrm{Ga}$-peptide PET/CT is recommended in

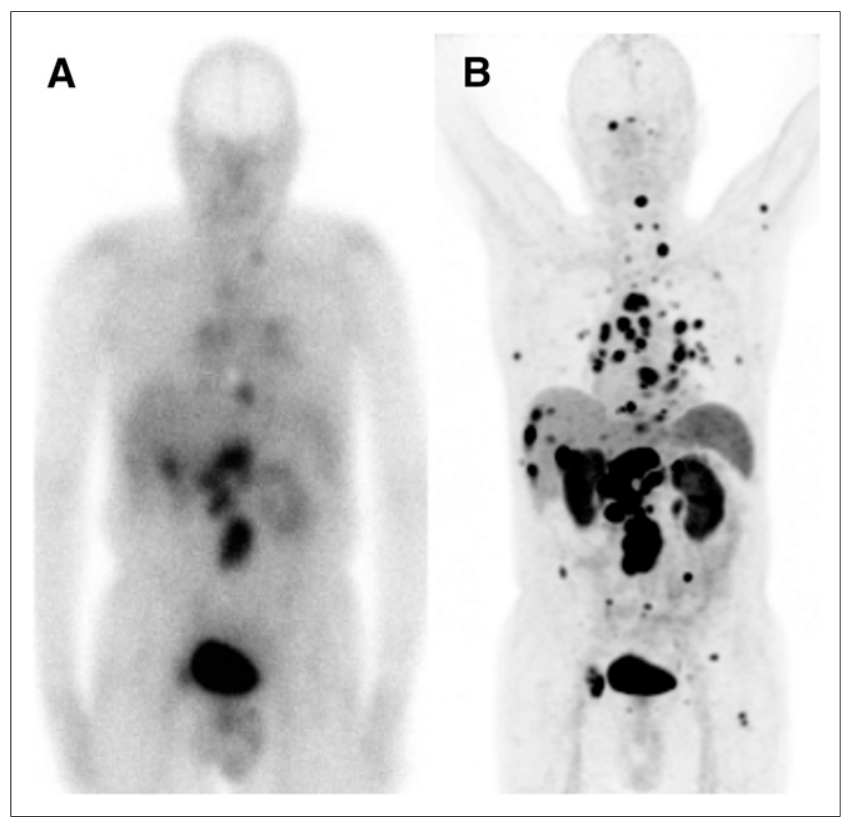

FIGURE 1. Head-to-head comparison of ${ }^{111}$ In-pentetreotide SSTR scintigraphy (A) and ${ }^{68} \mathrm{Ga}$-DOTATATE (B) PET/CT in patient with metastatic low-grade cecal NET evaluated before PRRT. In liver, retroperitoneal and thoracic lymph nodes, and bones, PET/CT shows multiple metastases, many of which are undetectable on SSTR scintigraphy.

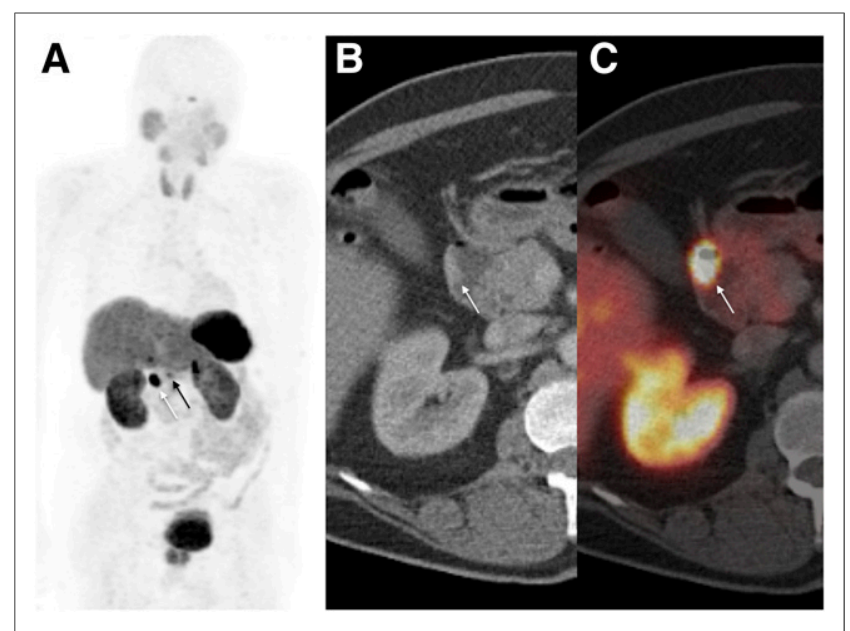

FIGURE 2. ${ }^{68} \mathrm{Ga}-\mathrm{DOTATATE} \mathrm{PET/CT}$ results (A: anterior PET maximumintensity projection, B: axial CT scan, C: axial PET/CT scan) in patient referred for preoperative staging of low-grade duodenal NET (white arrows) appearing as nodular thickening of lateral wall of duodenum with contrast enhancement and intense radiotracer uptake. ${ }^{68} \mathrm{Ga}-$ DOTATATE PET/CT also shows additional pathologic focal uptake in epigastric region corresponding to synchronous duodenal G1 NET (black arrow).

all patients presenting with a neuroendocrine cancer of unknown primary. PET/CT with ${ }^{68} \mathrm{Ga}$-peptides has also been shown to have high accuracy for diagnosing recurrence in NET patients. Haug's group showed a $90 \%$ sensitivity and $82 \%$ specificity in a series of 63 patients with 29 documented relapses. In that study, the reasons for PET/CT were regular follow-up, an increase in tumor marker, or clinical suspicion of relapse (23).

Although there are some differences in the affinity profiles between ${ }^{68} \mathrm{Ga}$-DOTATOC, ${ }^{68} \mathrm{Ga}$-DOTATATE, and ${ }^{68} \mathrm{Ga}$-DOTANOC, comparative studies using the same patient population have shown only minor differences in lesion detection rate. A recent metaanalysis (24) concluded that both ${ }^{68} \mathrm{Ga}$-DOTATOC and ${ }^{68} \mathrm{Ga}$-DOTATATE have high diagnostic accuracy (sensitivity of $93 \%$ and $96 \%$, respectively, and specificity of $85 \%$ and $100 \%$, respectively). In a head-tohead comparison of ${ }^{68} \mathrm{Ga}$-DOTATOC and ${ }^{68} \mathrm{Ga}$-DOTATATE in the same patients $(n=40), 262$ and 254 lesions $(97 \%)$ were detected with an average SUV of 20.4 and 16.0, respectively (25). In a similar comparison of ${ }^{68} \mathrm{Ga}$-DOTATATE and ${ }^{68} \mathrm{Ga}$-DOTANOC $(n=20)$, 130 and 116 lesions (89\%) were detected, with an average $\mathrm{SUV}_{\max }$ of 29.9 and 24.5 , respectively (26).

In clinical practice, the benefit of using ${ }^{68} \mathrm{Ga}$-DOTA-peptide PET imaging versus ${ }^{111}$ In-pentetreotide SPECT imaging is mainly due to detection of smaller lesions; detection of lesions with lowto-moderate SSTR expression; detection of more lesions, which will potentially direct to a different therapeutic choice; faster imaging procedure; lower exposure of patients to radiation (the effective dose for a typical $100-\mathrm{MBq}$ administration of ${ }^{68} \mathrm{Ga}$-DOTATATE or ${ }^{68} \mathrm{Ga}$-DOTATOC is $2.1 \mathrm{mSv}$ (27), vs. $7.3 \mathrm{mSv}$ for $100 \mathrm{MBq}$ of ${ }^{111}$ In-pentetreotide (28)); and detection of occult primary tumors in up to $30 \%-60 \%$ of patients with negative findings on conventional imaging. Caution is necessary when comparing ${ }^{68} \mathrm{Ga}$-DOTA-peptide PET results with previous ${ }^{111}$ In-pentetreotide imaging in a patient, as new lesions do not necessarily indicate disease progression.

${ }^{68} \mathrm{Ga}$-peptide PET has similar benefits for imaging nonpancreatic and pancreatic NETs (Figs. $1-3$ ). ${ }^{68} \mathrm{Ga}$-peptide PET is also sensitive 
in patients with multiple endocrine neoplasia type 1 . A comparison of ${ }^{68} \mathrm{Ga}$-DOTATOC versus ${ }^{111} \mathrm{In}$-pentetreotide and contrast-enhanced CT in 19 patients with multiple endocrine neoplasia type 1 showed sensitivity of $76 \%$ for detection of NETs by ${ }^{68} \mathrm{Ga}$-DOTATOC, versus $20 \%$ for ${ }^{111}$ In-pentetreotide and $60 \%$ for contrast-enhanced CT (29). ${ }^{68} \mathrm{Ga}$-DOTATOC detected 46 pancreatic tumors, ${ }^{111} \mathrm{In}$-pentetreotide detected 11 , and contrast-enhanced CT detected 37 . In a prospective study evaluating ${ }^{68} \mathrm{Ga}$-DOTATATE versus ${ }^{111} \mathrm{In}$-pentetreotide and contrast-enhanced CT in 26 patients with multiple endocrine neoplasia type $1,{ }^{68} \mathrm{Ga}$-DOTATATE PET/CT detected 107 lesions, ${ }^{111}$ In-pentetreotide SPECT/CT detected 33 lesions, and CT detected 48 lesions (30). In 8 of the 26 patients (31\%), there was a change in management recommendations as a result of findings on ${ }^{68} \mathrm{Ga}$-DOTATATE PET/CT that were not seen on ${ }^{111}$ In-pentetreotide SPECT/CT or CT.

Insulinoma detection through SSTR imaging has classically been associated with a low sensitivity, but recent results show that in more than $85 \%$ of patients, ${ }^{68} \mathrm{Ga}$-peptide PET can detect sources for endogenous pancreatic hypoglycemia, including benign and malignant insulinomas and nesidioblastosis (31).

Theranostic imaging of SSTRs is a prominent indication for SSTR scintigraphy and ${ }^{68}$ Ga-DOTA-peptide PET/CT. Sufficient levels of SSTR expression have to be documented before peptide receptor radionuclide therapy (PRRT) is recommended (32). Traditionally, ${ }^{111}$ In-pentetreotide uptake in tumor lesions was compared with normal liver uptake on planar images. However, ${ }^{68} \mathrm{Ga}-$ DOTA-peptide PET/CT offers straightforward quantitation, which potentially allows for a more robust patient selection than visual assessment. Several groups have shown that uptake on baseline ${ }^{68} \mathrm{Ga}$-DOTA-peptide PET/CT can predict the delivered absorbed dose or the response after PRRT. Ezziddin et al. (33) evaluated 61 lesions in 21 patients treated with ${ }^{177} \mathrm{Lu}$-DOTATATE and found a

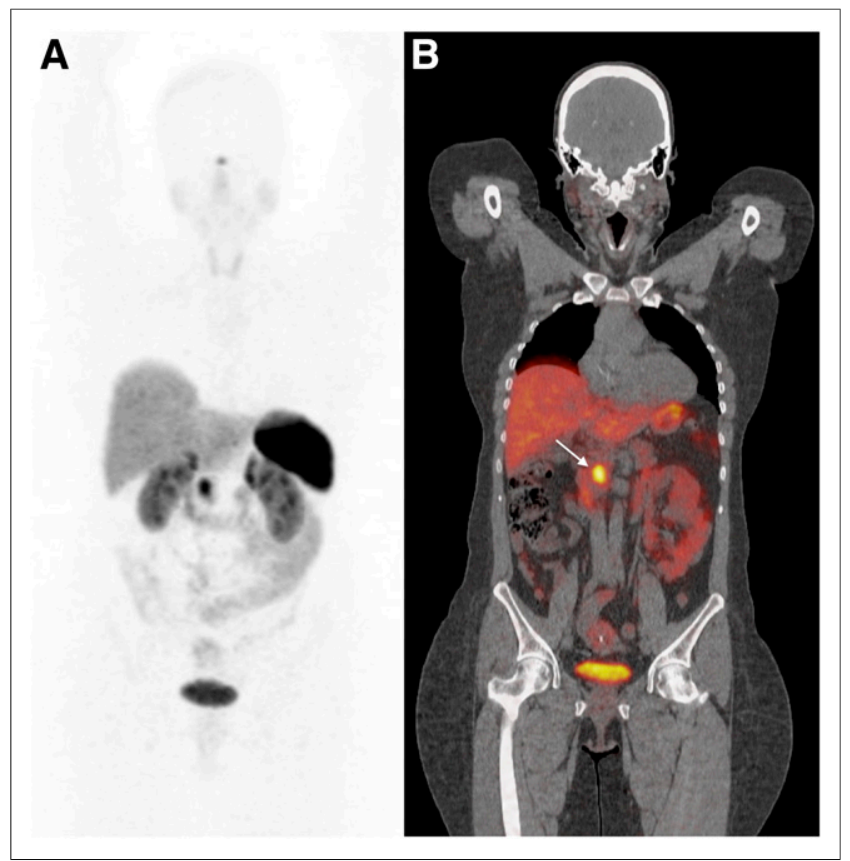

FIGURE 3. ${ }^{68} \mathrm{Ga}$-DOTATATE PET/CT results (A: anterior PET maximumintensity projection, B: coronal PET/CT scan) in patient with nonfunctional G1 NET of pancreatic head referred for primary staging. Tumor exhibited highly elevated uptake of ${ }^{68} \mathrm{G}$-DOTATATE (arrow) without locoregional or distant metastasis. significant correlation between ${ }^{68} \mathrm{Ga}$-DOTATOC $\mathrm{SUV}_{\max }$ or $\mathrm{SUV}_{\text {mean }}$ and the tumor-absorbed dose during the first treatment cycle. Kratochwil et al. (34) found that an $\mathrm{SUV}_{\max }$ above 16.4 on ${ }^{68} \mathrm{Ga}$-DOTATOC PET/CT before PRRT $\left({ }^{90}\right.$ Y-DOTATOC or ${ }^{177} \mathrm{Lu}-$ DOTATATE) was a sensitive predictor of lesion stabilization or shrinkage of liver metastases in 30 patients. Further prospective studies are warranted to define semiquantitative thresholds below which the probability of benefit from PRRT is sufficiently low to refrain from treatment.

It is currently unclear whether assessing the response to PRRT with ${ }^{68} \mathrm{Ga}$-DOTA-peptides, either after one treatment cycle or at the end of treatment, offers an advantage over conventional anatomic imaging alone, since studies on this topic have yielded mixed results (35-37).

Pitfalls of SSTR PET include misinterpretation of the physiologic uptake in the pancreatic head and uncinate process as a NET; misinterpretation of an accessory spleen, intrapancreatic spleen, or splenosis as NET metastases; and misinterpretation of mild-tomoderate inflammatory uptake as metastatic disease, such as in inflammatory lymph nodes or osteoarthritis. Integration with anatomic information from PET/CT or PET/MRI helps to provide the right interpretation in most cases. The final interpretation should also consider other potential SSTR-expressing tumors, such as meningioma, neural crest tumors, and renal cell carcinoma.

Avenues for further optimization of SSTR PET/CT have recently been proposed. Radiolabeled antagonists can achieve higher uptake than the previously mentioned ligands, all of which are agonist analogs. As antagonists are independent of the activation status of the SSTR, they can bind to a higher number of receptors than agonists. Unlike agonists, antagonists are not internalized (38).

${ }^{68} \mathrm{Ga}$-DOTA-peptides require radiopharmacy equipment. Cassette systems are commercially available, and innovative strategies are currently being developed that would allow a more facile, kitlike on-site labeling. Some groups have used other positron emitters, such as ${ }^{64} \mathrm{Cu}$ (half-life, $12.7 \mathrm{~h}$ ) (39) or chelated $\mathrm{Al}^{18} \mathrm{~F}$ complexes (half-life, $110 \mathrm{~min}$ ), that would allow centralized production and distribution to peripheral sites (40).

\section{Radiolabeled MIBG}

${ }^{123}$ I- or ${ }^{131}$ I-labeled MIBG is a structural analog of norepinephrine. Following active transport mechanisms, MIBG accumulates in the secretory vesicles of NET cells. The sensitivity of MIBG scintigraphy for GEP NETs has been reported as close to $50 \%$ (14). ${ }^{123} \mathrm{I}$ - or ${ }^{131} \mathrm{I}$-MIBG can be used as a theranostic approach in GEP NETs with a low SSTR expression pattern, since uptake may imply a potential response to ${ }^{131} \mathrm{I}-\mathrm{MIBG}$ therapy.

\section{${ }^{18}$ F-Fluorodihydroxyphenylalanine $\left({ }^{18} \mathrm{~F}-\mathrm{FDOPA}\right)$}

${ }^{18} \mathrm{~F}$-FDOPA PET/CT has been successfully used for NET imaging (41). Once internalized via the sodium-independent system $\mathrm{L},{ }^{18} \mathrm{~F}$-FDOPA is decarboxylated to ${ }^{18} \mathrm{~F}$-dopamine, transported, and stored in cellular neurosecretory granules. A recently proposed radiosynthesis process based on nucleophilic substitution would allow the production of high-specific-activity ${ }^{18} \mathrm{~F}$ FDOPA (42).

${ }^{18}$ F-FDOPA PET/CT sensitivity is low (25\%) in high-grade GEP NETs and NETs arising from the foregut and hindgut (43). In contrast, ${ }^{18} \mathrm{~F}$-FDOPA PET/CT has excellent sensitivity in low-grade ileal NETs (Fig. 4). The increased activity of aromatic L-amino acid decarboxylase, involved in tumoral biosynthesis of serotonin, explains this high sensitivity in carcinoids. In these cases, ${ }^{18} \mathrm{~F}$-FDOPA PET/CT can be helpful for tumor localization and staging (44). At 


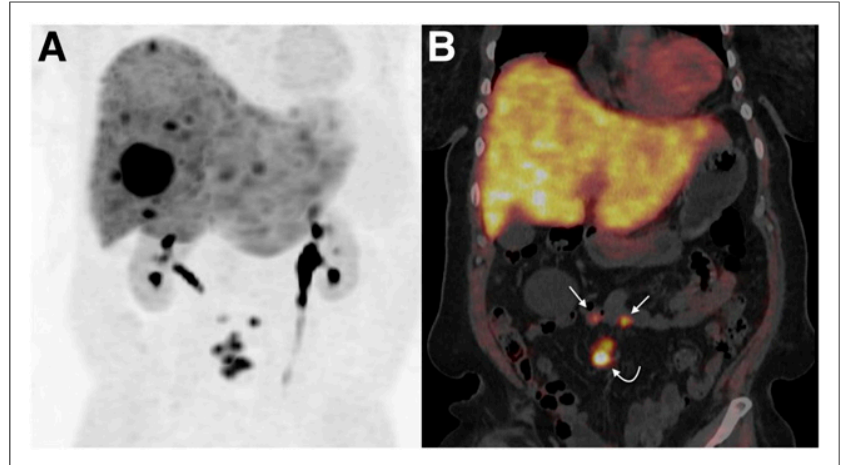

FIGURE 4. ${ }^{18} \mathrm{~F}-\mathrm{FDOPA} P E T / C T$ results (A: anterior PET maximumintensity projection, B: coronal PET/CT scan) in patient with carcinoid syndrome, retractile mesenteric lesions (curved arrow), and hepatic metastases of low-grade NET of unknown origin. Conventional imaging and ${ }^{111}$ In-pentetreotide SSTR scintigraphy failed to detect primary site. ${ }^{18} \mathrm{~F}$ FDOPA PET/CT depicted 2 pathologic foci in ileum (straight arrows). Pathologic examination after surgery confirmed diagnosis of bifocal ileal G1 NET.

present, there are no recommendations on the use of ${ }^{18} \mathrm{~F}-\mathrm{FDOPA}$ PET/CT during follow-up.

${ }^{18} \mathrm{~F}$-FDOPA PET/CT is superior to both CT and ${ }^{111}$ In-pentetreotide SSTR scintigraphy for the detection of lymph nodes, skeletal lesions, and liver metastases in patients with low-grade midgut NETs (44). On the other hand, the advantages of ${ }^{18} \mathrm{~F}-\mathrm{FDOPA}$ PET/CT over ${ }^{68} \mathrm{Ga}$-DOTA-peptide PET/CT in patients with midgut NETs are still unclear, and large prospective studies are necessary (45). Undoubtedly, ${ }^{68} \mathrm{Ga}$-DOTA-peptide PET/CT offers an advantage over ${ }^{18}$ F-FDOPA due to the ability to assess the feasibility of performing PRRT.

${ }^{18} \mathrm{~F}$-FDOPA PET/CT appears to be a sensitive functional imaging tool for the detection of ileal primary NETs occult on conventional imaging or SSTR scintigraphy (Fig. 4) (46). The localization of the primary tumor may be challenging but remains crucial for treatment planning since surgical resection is associated with better symptomfree survival, overall survival, and quality of life, even in patients with metastatic disease (47). The choice of tracer to be used first depends on presumption of origin based on clinical evaluation, laboratory evaluation, and studies of immunohistochemical markers on biopsy samples of metastatic tissue.

${ }^{18}$ F-FDOPA has a low sensitivity for detecting small primary tumors in the pancreas and duodenum and is generally less sensitive than ${ }^{68} \mathrm{Ga}$-DOTA-peptide PET/CT, except for insulinomas, which can express low levels of SSTRs. One of the difficulties with ${ }^{18} \mathrm{~F}$ FDOPA is high uptake and retention by the mature exocrine pancreas. These might be inhibited by administering carbidopa (a peripheral aromatic L-amino acid decarboxylase inhibitor) approximately $2 \mathrm{~h}$ before ${ }^{18} \mathrm{~F}$-FDOPA injection. A combination of carbidopa premedication and early PET/CT acquisition (5 min after injection) might improve detection of adult insulinoma (Fig. 5) (48). Since glucagonlike peptide-1 receptors are overexpressed in most benign insulinomas, SPECT/CT or PET/CT radiolabeled glucagonlike peptide-1 analogs showing excellent results have been developed, but their use remains confined to few centers $(11,49,50)$.

\section{${ }^{18}$ F-FDG}

${ }^{18}$ F-FDG PET/CT measures tumoral glycolytic activity. Once internalized by glucose transporters (mainly transporters 1 and 3),
${ }^{18} \mathrm{~F}-\mathrm{FDG}$ is phosphorylated by hexokinase without further metabolic processes and remains trapped within the cytoplasm.

${ }^{18} \mathrm{~F}-\mathrm{FDG}$ PET/CT is considered the preferred radiotracer for $\mathrm{G} 3$ tumors, as well as for some high-grade $\mathrm{G} 2$ tumors. The role of ${ }^{18} \mathrm{~F}$ FDG PET/CT in G1 tumors or in low-grade G2 tumors is still debated (51). A Ki-67 of at least $10 \%$ is often considered the cutoff for proposing the use of ${ }^{18} \mathrm{~F}-\mathrm{FDG}$ PET/CT for welldifferentiated G2 NETs (52). ${ }^{18} \mathrm{~F}-\mathrm{FDG}$ PET/CT has a potential value for prognostic stratification $(53,54)$. NETs with increased ${ }^{18} \mathrm{~F}-\mathrm{FDG}$ uptake are more aggressive and less favorable to longterm survival, supporting the evidence that an increased glycolytic rate reveals a worse prognosis. ${ }^{18} \mathrm{~F}-\mathrm{FDG} \mathrm{PET} / \mathrm{CT}$ seems more sensitive than tumor differentiation or Ki-67 in the early prediction of progressive low-grade NETs. Therefore, metabolic grading based on ${ }^{18} \mathrm{~F}$-FDG PET/CT has been proposed in patients with metastatic GEP NETs, and this grading has shown a high predictive power for overall survival (55).

\section{TOWARD PERSONALIZED MEDICINE}

\section{Proposed Imaging Algorithm}

A simplified algorithm for the use of imaging procedures in GEP NET patients is proposed in Figure 6. The choice of morphologic and functional imaging can be made according to clinical symptoms, tumor site of origin, grade, availability of tracers, and local expertise.

\section{Therapeutic Decision Making}

GEP NET patients should be referred to (or at a minimum their case discussed by) a multidisciplinary skilled team for evaluation, treatment, and follow-up (56). Whenever feasible, surgery (including resection of liver metastases) should be contemplated for low-grade tumors. Multiple therapeutic options are available for unresectable

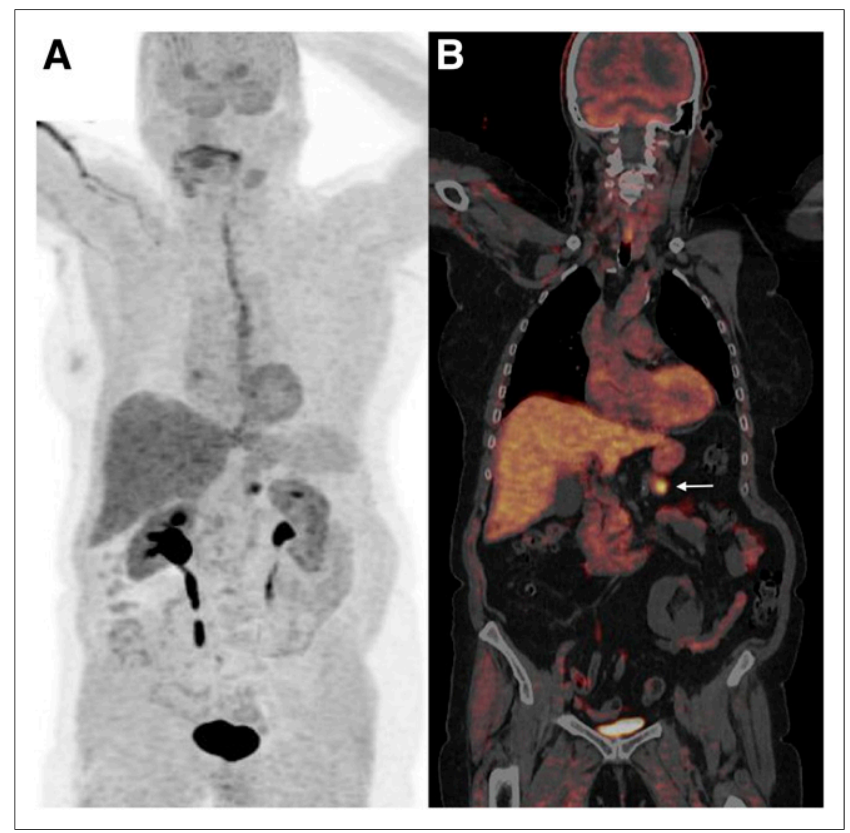

FIGURE 5. ${ }^{18} \mathrm{~F}-\mathrm{FDOPA}$ PET/CT after carbidopa premedication (A: anterior PET maximum-intensity projection, B: coronal PET/CT scan) in patient with hyperinsulinemic hypoglycemia. Insulinoma (arrow) was clearly identified by PET/CT. Normal pancreatic parenchyma has low uptake because of premedication by carbidopa. 


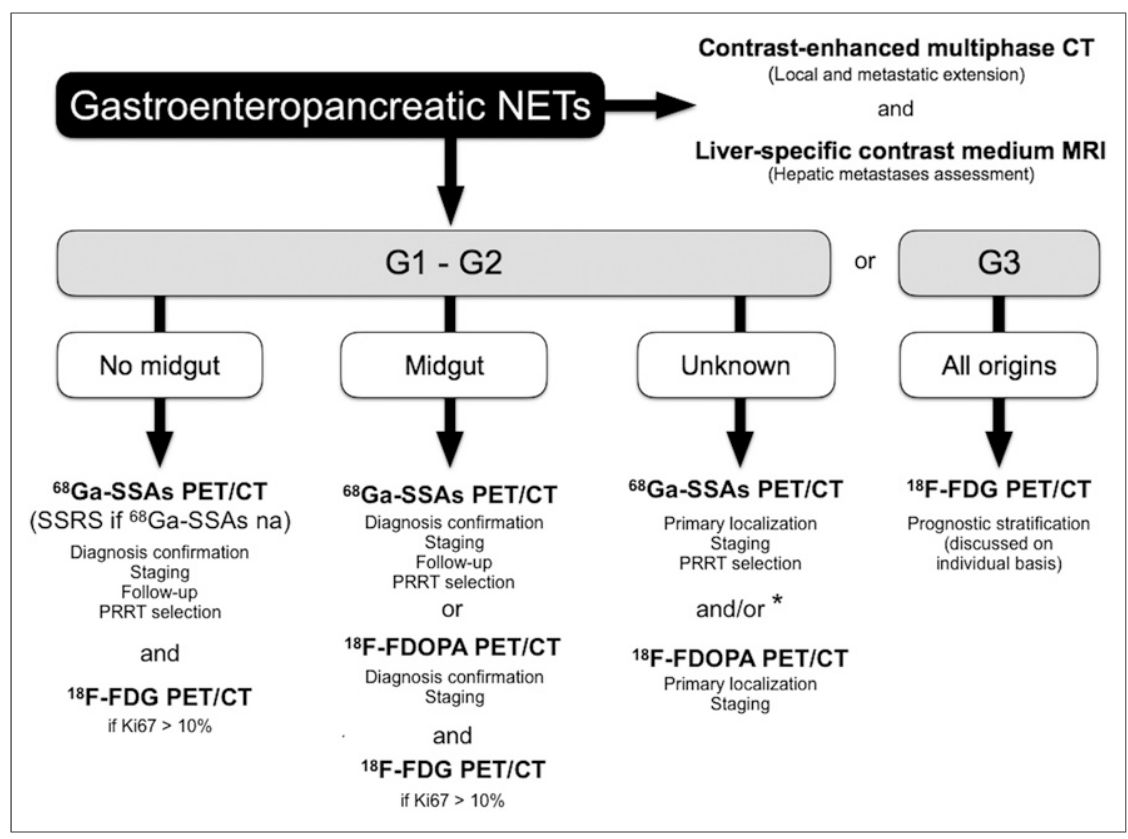

FIGURE 6. Proposed diagnostic imaging algorithm for patients with GEP NETs. na = not available; SSRS $=$ SSTR scintigraphy. ${ }^{*}$ Based on presumption of origin and hormonal secretion if present. treatment options. Moreover, there is a potential relationship between the tumor grade and the results of functional imaging by radiolabeled SSAs (or ${ }^{18} \mathrm{~F}-\mathrm{FDOPA}$ ) and ${ }^{18}$ F-FDG PET/CT, usually called the flipflop phenomenon. The mismatch represented by high uptake of radiolabeled SSAs (or ${ }^{18}$ F-FDOPA) and low uptake of ${ }^{18}$ F-FDG is widely considered the functional imaging pattern of low-grade GEP NETs. Conversely, low uptake of radiolabeled SSAs (or ${ }^{18} \mathrm{~F}$-FDOPA) and high uptake of ${ }^{18} \mathrm{~F}$ FDG is representative of high-grade tumors (Fig. 7).

\section{Theranostics: The Image-and-Treat Attitude}

The term theranostics that has been introduced to the field of personalized medicine summarizes the integration of diagnostics and therapeutics in patient management. $\mathrm{Nu}-$ clear medicine is ideally situated to play a central role in theranostics. For example, SSR imaging allows physicians to determine the presence of a functional target before treatment with cold somatostatin analogs advanced disease or metastatic disease from well-differentiated (G1 and G2) tumors, including medical treatment with somatostatin analogs, PRRT, chemotherapy, and molecule-targeted therapies such as mammalian target of rapamycin inhibitors and antiangiogenic agents. The strategy of their use differs between pancreatic and nonpancreatic NETs. Chemoembolization, radiofrequency ablation, and selective internal radiotherapy also represent valuable options for unresectable liver-dominant metastases. Patients with unresectable, isolated liver metastases may also be considered for liver transplantation. Highgrade tumors are treated mainly by chemotherapy (57).

Management of GEP NET patients depends on tumor grade and SSTR expression. Molecular imaging is helpful for detecting tumor heterogeneity and for guiding clinicians toward the best

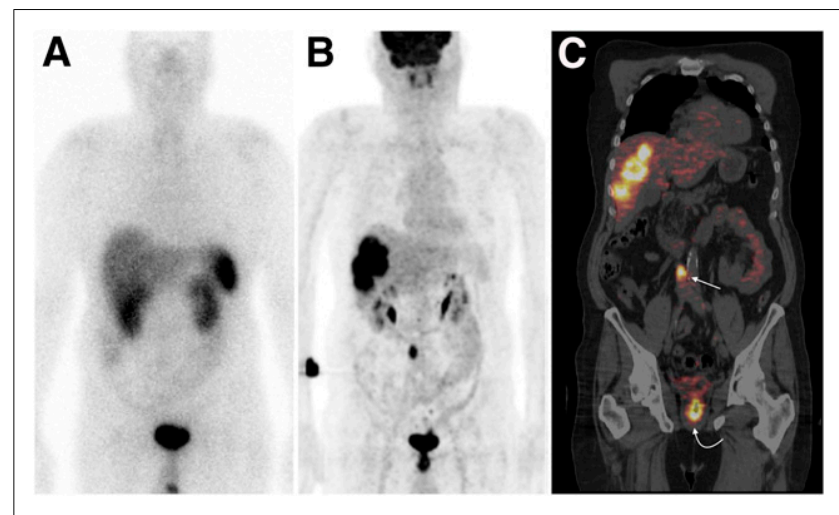

FIGURE 7. Typical example of flip-flop phenomenon in molecular imaging of patient with hepatic metastasis from G3 NET of unknown origin and referred before therapeutic strategy planning. Shown are ${ }^{111} \mathrm{In}$-pentetreotide SSTR scintigram (A), anterior ${ }^{18} \mathrm{~F}-\mathrm{FDG}$ PET maximum-intensity projection (B), and coronal PET/CT scan (C). ${ }^{18} \mathrm{~F}-\mathrm{FDG}$ PET/CT showed intense uptake by hepatic lesions and allowed detection of primary rectal tumor (curved arrow) and retroperitoneal lymphatic metastasis (straight arrow). These high-grade lesions showed no uptake on SSTR scintigraphy.
(58). Peptide receptor targeting for theranostics in nuclear medicine is an excellent illustration of patient-specific therapy based on the image-and-treat approach. The excellent results obtained from the NETTER-1 trial (59) will provide a powerful impetus for wider application of ${ }^{177} \mathrm{Lu}$-DOTATATE therapy in patients with metastatic or inoperable progressive intestinal G1 and G2 GEP NETs despite SSA treatment. Randomized studies on pancreatic NETs are also ongoing.

\section{CONCLUSION}

Here, we have emphasized the evolving role of nuclear medicine imaging in the management of GEP NETs, enabling a better understanding of tumor pathophysiology and hopefully offering to these patients more precise treatments and improved outcomes.

\section{REFERENCES}

1. Yao JC, Hassan M, Phan A, et al. One hundred years after "carcinoid": epidemiology of and prognostic factors for neuroendocrine tumors in 35,825 cases in the United States. J Clin Oncol. 2008;26:3063-3072.

2. Fraenkel M, Kim MK, Faggiano A, Valk GD. Epidemiology of gastroenteropancreatic neuroendocrine tumours. Best Pract Res Clin Gastroenterol. 2012;26:691-703.

3. Delle Fave G, O'Toole D, Sundin A, et al. ENETS consensus guidelines update for gastroduodenal neuroendocrine neoplasms. Neuroendocrinology. 2016;103:119-124.

4. Falconi M, Eriksson B, Kaltsas G, et al. ENETS consensus guidelines update for the management of patients with functional pancreatic neuroendocrine tumors and nonfunctional pancreatic neuroendocrine tumors. Neuroendocrinology. 2016;103:153-171.

5. Niederle B, Pape UF, Costa F, et al. ENETS consensus guidelines update for neuroendocrine neoplasms of the jejunum and ileum. Neuroendocrinology. 2016; 103:125-138.

6. Ramage JK, De Herder WW, Delle Fave G, et al. ENETS consensus guidelines update for colorectal neuroendocrine neoplasms. Neuroendocrinology. 2016;103:139-143.

7. Rindi G, Petrone G, Inzani F. The 2010 WHO classification of digestive neuroendocrine neoplasms: a critical appraisal four years after its introduction. Endocr Pathol. 2014;25:186-192.

8. Vélayoudom-Céphise FL, Duvillard P, Foucan L, et al. Are G3 ENETS neuroendocrine neoplasms heterogeneous? Endocr Relat Cancer. 2013;20:649-657.

9. Klöppel G, Rindi G, Perren A, Komminoth P, Klimstra DS. The ENETS and AJCC/UICC TNM classifications of the neuroendocrine tumors of the gastro- 
intestinal tract and the pancreas: a statement. Virchows Arch. 2010;456:595597.

10. Luo G, Javed A, Strosberg JR, et al. Modified staging classification for pancreatic neuroendocrine tumors on the basis of the American Joint Committee on Cancer and European Neuroendocrine Tumor Society systems. J Clin Oncol. September 19, 2016 [Epub ahead of print].

11. Baumann T, Rottenburger C, Nicolas G, Wild D. Gastroenteropancreatic neuroendocrine tumors (GEP-NET): imaging and staging. Best Pract Res Clin Endocrinol Metab. 2016;30:45-57.

12. Sundin A. Radiological and nuclear medicine imaging of gastroenteropancreatic neuroendocrine tumours. Best Pract Res Clin Gastroenterol. 2012;26:803-818.

13. Weckbecker G, Lewis I, Albert R, et al. Opportunities in somatostatin research: biological, chemical and therapeutic aspects. Nat Rev Drug Discov. 2003;2:999-1017.

14. Binderup T, Knigge U, Loft A, et al. Functional imaging of neuroendocrine tumors: a head-to-head comparison of somatostatin receptor scintigraphy, ${ }^{123} \mathrm{I}$ MIBG scintigraphy, and ${ }^{18}$ F-FDG PET. J Nucl Med. 2010;51:704-712.

15. Reubi JC, Schar JC, Waser B, et al. Affinity profiles for human somatostatin receptor subtypes SST1-SST5 of somatostatin radiotracers selected for scintigraphic and radiotherapeutic use. Eur J Nucl Med. 2000;27:273-282.

16. Wild D, Mäcke HR, Waser B, et al. ${ }^{68}$ Ga-DOTANOC: a first compound for PET imaging with high affinity for somatostatin receptor subtypes 2 and 5 [case report]. Eur J Nucl Med Mol Imaging. 2005;32:724.

17. Velikyan I, Sundin A, Sörensen J, et al. Quantitative and qualitative intrapatient comparison of ${ }^{68} \mathrm{Ga}$-DOTATOC and ${ }^{68} \mathrm{Ga}$-DOTATATE: net uptake rate for accurate quantification. $J$ Nucl Med. 2014;55:204-210.

18. Sadowski SM, Neychev V, Millo C, et al. Prospective study of ${ }^{68}$ Ga-DOTATATE positron emission tomography/computed tomography for detecting gastro-enteropancreatic neuroendocrine tumors and unknown primary sites. J Clin Oncol. 2016;34:588-596.

19. Frilling A, Sotiropoulos GC, Radtke A, et al. The impact of ${ }^{68}$ Ga-DOTATOC positron emission tomography/computed tomography on the multimodal management of patients with neuroendocrine tumors. Ann Surg. 2010;252:850-856.

20. Ruf J, Heuck F, Schiefer J, et al. Impact of multiphase ${ }^{68} \mathrm{Ga}$-DOTATOC-PET/CT on therapy management in patients with neuroendocrine tumors. Neuroendocrinology. 2010;91:101-109.

21. Kazmierczak PM, Rominger A, Wenter V, et al. The added value of ${ }^{68} \mathrm{Ga}$-DOTA-TATE-PET to contrast-enhanced CT for primary site detection in CUP of neuroendocrine origin. Eur Radiol. July 19, 2016 [Epub ahead of print].

22. Alonso O, Rodríguez-Taroco M, Savio E, Bentancourt C, Gambini JP, Engler H. ${ }^{68} \mathrm{Ga}$-DOTATATE PET/CT in the evaluation of patients with neuroendocrine metastatic carcinoma of unknown origin. Ann Nucl Med. 2014;28:638-645.

23. Haug AR, Cindea-Drimus R, Auernhammer CJ, et al. Neuroendocrine tumor recurrence: diagnosis with ${ }^{68}$ Ga-DOTATATE PET/CT. Radiology. 2014;270:517-525.

24. Yang J, Kan Y, Ge BH, et al. Diagnostic role of gallium-68 DOTATOC and gallium-68 DOTATATE PET in patients with neuroendocrine tumors: a metaanalysis. Acta Radiol. 2014;55:389-398.

25. Poeppel TD, Binse I, Petersenn S, et al. ${ }^{68} \mathrm{Ga}$-DOTATOC versus ${ }^{68} \mathrm{Ga}$-DOTATATE PET/ CT in functional imaging of neuroendocrine tumors. J Nucl Med. 2011;52:1864-1870.

26. Kabasakal L, Demirci E, Ocak M, et al. Comparison of ${ }^{68} \mathrm{Ga}$-DOTATATE and ${ }^{68} \mathrm{Ga}$-DOTANOC PET/CT imaging in the same patient group with neuroendocrine tumours. Eur J Nucl Med Mol Imaging. 2012;39:1271-1277.

27. Sandström M, Velikyan I, Garske-Román U, et al. Comparative biodistribution and radiation dosimetry of ${ }^{68} \mathrm{Ga}$-DOTATOC and ${ }^{68} \mathrm{Ga}$-DOTATATE in patients with neuroendocrine tumors. J Nucl Med. 2013;54:1755-1759.

28. Stabin MG, Kooij PP, Bakker WH, et al. Radiation dosimetry for indium-111pentetreotide. J Nucl Med. 1997;38:1919-1922.

29. Morgat C, Vélayoudom-Céphise FL, Schwartz P, et al. Evaluation of ${ }^{68} \mathrm{Ga}$-DOTATOC PET/CT for the detection of duodenopancreatic neuroendocrine tumors in patients with MEN1. Eur J Nucl Med Mol Imaging. 2016;43:1258-1266.

30. Sadowski SM, Millo C, Cottle-Delisle C, et al. Results of ${ }^{68}$ gallium-DOTATATE PET/CT scanning in patients with multiple endocrine neoplasia type 1. J Am Coll Surg. 2015;221:509-517.

31. Prasad V, Sainz-Esteban A, Arsenic R, et al. Role of ${ }^{68} \mathrm{Ga}$ somatostatin receptor PET/CT in the detection of endogenous hyperinsulinaemic focus: an explorative study. Eur J Nucl Med Mol Imaging. 2016;43:1593-1600.

32. Bodei L, Mueller-Brand J, Baum RP, et al. The joint IAEA, EANM, and SNMMI practical guidance on peptide receptor radionuclide therapy (PRRNT) in neuroendocrine tumours. Eur J Nucl Med Mol Imaging. 2013;40:800-816.

33. Ezziddin S, Lohmar J, Yong-Hing CJ, et al. Does the pretherapeutic tumor SUV in ${ }^{68} \mathrm{Ga}$ DOTATOC PET predict the absorbed dose of ${ }^{177} \mathrm{Lu}$ octreotate? Clin Nucl Med. 2012;37:e141-e147.
34. Kratochwil C, Stefanova M, Mavriopoulou E, et al. SUV of [ $\left.{ }^{68} \mathrm{Ga}\right]$ DOTATOCPET/CT predicts response probability of PRRT in neuroendocrine tumors. Mol Imaging Biol. 2015;17:313-318.

35. Haug AR, Auernhammer CJ, Wängler B, et al. ${ }^{68} \mathrm{Ga}$-DOTATATE PET/CT for the early prediction of response to somatostatin receptor-mediated radionuclide therapy in patients with well-differentiated neuroendocrine tumors. J Nucl Med. 2010;51:1349-1356.

36. Gabriel M, Oberauer A, Dobrozemsky G, et al. ${ }^{68}$ Ga-DOTA-Tyr3-octreotide PET for assessing response to somatostatin-receptor-mediated radionuclide therapy. $J$ Nucl Med. 2009;50:1427-1434.

37. Wulfert S, Kratochwil C, Choyke PL, et al. Multimodal imaging for early functional response assessment of ${ }^{90} \mathrm{Y}-/^{177} \mathrm{Lu}$-DOTATOC peptide receptor targeted radiotherapy with DW-MRI and ${ }^{68}$ Ga-DOTATOC-PET/CT. Mol Imaging Biol. 2014;16:586-594.

38. Wild D, Fani M, Behe M, et al. First clinical evidence that imaging with somatostatin receptor antagonists is feasible. J Nucl Med. 2011;52:1412-1417.

39. Pfeifer A, Knigge U, Binderup T, et al. ${ }^{64} \mathrm{Cu}$-DOTATATE PET for neuroendocrine tumors: a prospective head-to-head comparison with ${ }^{111}$ In-DTPA-octreotide in 112 patients. J Nucl Med. 2015;56:847-854.

40. Laverman P, McBride WJ, Sharkey RM, et al. A novel facile method of labeling octreotide with ${ }^{18}$ F-fluorine. J Nucl Med. 2010;51:454-461.

41. Minn H, Kauhanen S, Seppänen M, Nuutila P. ${ }^{18}$ F-FDOPA: a multiple-target molecule. J Nucl Med. 2009;50:1915-1918.

42. Kuik WJ, Kema IP, Brouwers AH, et al. In vivo biodistribution of no-carrier-added $6-{ }^{18} \mathrm{~F}$-fluoro-3,4-dihydroxy-L-phenylalanine ( ${ }^{18} \mathrm{~F}$-DOPA), produced by a new nucleophilic substitution approach, compared with carrier-added ${ }^{18} \mathrm{~F}$-DOPA, prepared by conventional electrophilic substitution. J Nucl Med. 2015;56:106-112.

43. Montravers F, Kerrou K, Nataf V, et al. Impact of fluorodihydroxyphenylalanine- ${ }^{18} \mathrm{~F}$ positron emission tomography on management of adult patients with documented or occult digestive endocrine tumors. J Clin Endocrinol Metab. 2009;94:1295-1301.

44. Koopmans KP, de Vries EG, Kema IP, et al. Staging of carcinoid tumours with ${ }^{18}$ FDOPA PET: a prospective, diagnostic accuracy study. Lancet Oncol. 2006;7:728-734.

45. Haug A, Auernhammer CJ, Wangler B, et al. Intraindividual comparison of ${ }^{68} \mathrm{Ga}-$ DOTA-TATE and ${ }^{18} \mathrm{~F}$-DOPA PET in patients with well-differentiated metastatic neuroendocrine tumours. Eur J Nucl Med Mol Imaging. 2009;36:765-770.

46. Imperiale A, Rust E, Gabriel S, et al. ${ }^{18}$ F-fluorodihydroxyphenylalanine PET/CT in patients with neuroendocrine tumors of unknown origin: relation to tumor origin and differentiation. J Nucl Med. 2014;55:367-372.

47. Rothenstein J, Clearly SP, Pond GR, et al. Neuroendocrine tumors of the gastrointestinal tract: a decade of experience at the Princess Margaret Hospital. Am J Clin Oncol. 2008;31:64-70.

48. Imperiale A, Sebag F, Vix M, et al. ${ }^{18}$ F-FDOPA PET/CT imaging of insulinoma revisited. Eur J Nucl Med Mol Imaging. 2015;42:409-418.

49. Christ E, Wild D, Ederer S, et al. Glucagon-like peptide-1 receptor imaging for the localisation of insulinomas: a prospective multicentre imaging study. Lancet Diabetes Endocrinol. 2013;1:115-122.

50. Luo Y, Pan Q, Yao S, et al. Glucagon-like peptide-1 receptor PET/CT with ${ }^{68} \mathrm{Ga}-$ NOTA-exendin-4 for detecting localized insulinoma: a prospective cohort study. J Nucl Med. 2016;57:715-720.

51. Panagiotidis E, Alshammari A, Michopoulou S, et al. Comparison of the impact of ${ }^{68} \mathrm{Ga}$-DOTATATE and ${ }^{18} \mathrm{~F}$-FDG PET/CT on clinical management in patients with neuroendocrine tumors. J Nucl Med. August 11, 2016 [Epub ahead of print].

52. Abgral R, Leboulleux S, Deandreis D, et al. Performance of ${ }^{18}$ fluorodeoxyglucosepositron emission tomography and somatostatin receptor scintigraphy for high Ki67 $(>=10 \%)$ well-differentiated endocrine carcinoma staging. J Clin Endocrinol Metab. 2011;96:665-671.

53. Binderup T, Knigge U, Loft A, Federspiel B, Kjaer A. ${ }^{18}$ F-fluorodeoxyglucose positron emission tomography predicts survival of patients with neuroendocrine tumors. Clin Cancer Res. 2010;16:978-985.

54. Bahri H, Laurence L, Edeline J, et al. High prognostic value of ${ }^{18} \mathrm{~F}$-FDG PET for metastatic gastroenteropancreatic neuroendocrine tumors: a long-term evaluation. J Nucl Med. 2014;55:1786-1790.

55. Ezziddin S, Adler L, Sabet A, et al. Prognostic stratification of metastatic gastroenteropancreatic neuroendocrine neoplasms by ${ }^{18}$ F-FDG PET: feasibility of a metabolic grading system. J Nucl Med. 2014;55:1260-1266.

56. van Essen M, Sundin A, Krenning EP, Kwekkeboom DJ. Neuroendocrine tumours: the role of imaging for diagnosis and therapy. Nat Rev Endocrinol. 2014;10:102-114.

57. Pavel M, O'Toole D, Costa F, et al. Consensus guidelines update for the management of distant metastatic disease of intestinal, pancreatic, bronchial neuroendocrine neoplasms (NEN) and NEN of unknown primary site. Neuroendocrinology. 2016;103:172-185.

58. Caplin ME, Pavel M, Cwikla JB, et al. Lanreotide in metastatic enteropancreatic neuroendocrine tumors. $N$ Engl J Med. 2014;371:224-233.

59. SSA therapies: ${ }^{177} \mathrm{Lu}$-DOTATATE is a better one in NETTER-1. Nat Rev Clin Oncol. 2015;12:684. 